\title{
Landform Classification in Raster Geo-images
}

\author{
Marco Moreno, Serguei Levachkine, Miguel Torres, and Rolando Quintero
}

Geoprocessing Laboratory-Centre for Computing Research-National Polytechnic Institute, Mexico City, Mexico

\{marcomoreno, palych, mtorres, quintero\}@cic.ipn.mx

http://geo.cic.ipn.mx, http://geopro.cic.ipn.mx

\begin{abstract}
We present an approach to perform a landform classification of raster geo-images to obtain the semantics of DEMs. We consider the following raster layers: slope, profile curvature and plan curvature, which have been built to identify the intrinsic properties of the landscape. We use a multi-valued raster to integrate these layers. The attributes of the multi-valued raster are classified to identify the landform elements. The classification approach is used to find the terrain characteristics of the water movement. Moreover, we describe the mechanisms to compute the primary attributes of digital terrain model. The method has been implemented into Geographical Information System-ArcInfo, and applied for Tamaulipas State, Mexico.
\end{abstract}

\section{Introduction}

Nowadays, Geographical Information Systems (GIS) are powerful and useful tools as means of information, visualization and research or as decision making applications [1]. Since the mid-1980s, with increasing popularity of GIS technology and availability of Digital Elevation Models (DEM), the potential of using DEM in studies of surface processes has been widely recognized [2]. DEM is playing an important role in many technical fields of GIS development, including earth and environmental sciences, hazard reduction, civil engineering, forestry, landscape planning, and commercial display. DEM has been used to delineate drainage networks and watershed boundaries to compute slope characteristics and to produce flow paths [3].

Contrasting with the traditional topographic map methods, the GIS approaches are relatively easy to apply in a consistent way on large landscape areas, because they allow summation of terrain characteristics for any region. To automate the procedure of terrain analysis, new methods and algorithms have been developed. The advantage of DEM analysis is that only one static parameter has to be captured to describe landscape processes. DEM are used in the measurement of geometry and landform. DEM has traditionally been applied to identify watersheds, drainages, hillslopes and other terrain object groups. The characteristics of terrain are distinguished by spatial relationships among and can be characterized by both its composition and configuration. We usually note that DEM are directly computed from the elevation model and secondary compound attributes which involve combination of primary attributes and constitute physically the spatial variability of specific processes that are presented in the landscape. While, primary attributes include slope, aspect, plan and profile curvature, flow-path length, and upslope contributing area. Most of these topographic attributes are computed from directional derivatives of a topographic surface.

\footnotetext{
A. Sanfeliu et al. (Eds.): CIARP 2004, LNCS 3287, pp. 558-565, 2004.

(c) Springer-Verlag Berlin Heidelberg 2004
} 
DEM are treated as field functions that consider a value at any position in a two dimensional space [4]. DEM is a particular type of raster geo-images. This raster describes thematic aspects of the terrain, which are represented by attributes (see Fig. 1). The geometric characteristics of DEM are the following: resolution, origin of coordinates, number of rows and columns, and lowest and highest coordinates.

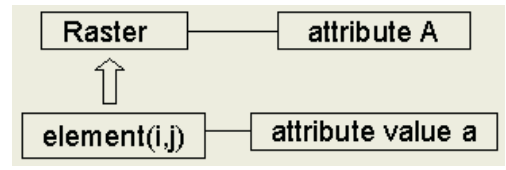

Fig. 1. Raster Data Model

In this paper, we propose an approach to make landform ${ }^{l}$ classification based on geo-image processing by means of Spatial Analyzer Module (SAM). In Section 2 we describe SAM and its functionality. Section 3 describes how landform classification has been obtained. Some results are shown in Section 5. Our conclusions are outlined in Section 6.

\section{Spatial Analyzer Module (SAM)}

SAM is a special module, which has been designed to perform the spatial analysis procedures. SAM uses vector and raster data to make the spatial analysis. This module has been implemented using Arc Macro Language (AML) to ensure portability between computer platforms executing ArcInfo 7.0 or later. Initially, SAM was designed to compute Terrain Ruggedness and Drainage Density [3]. The present analysis consists of using different spatial data related to the case of study. SAM contains two components: Analysis Block is composed of a set of processes to make data analysis, List of Procedures stores the sequence of steps to execute the processes [5].

\subsection{Analysis Block}

It contains the functions to perform the spatial analysis. The functions are the following:

Grid Functions. They contain the set of functions for cell analysis, which include operations of the map algebra and functions to compute primary topographic attributes such as slope, aspect, plan and profile curvature and upslope contributing area.

- Slope Function (CALCULATE_SLOPE): Slope identifies the maximum rate of change in value from each cell to its neighbors. An output slope grid can be computed as percent slope or degree of slope. Conceptually, the slope function fits a plane to the z-values (altitudes) of a 3 x 3 cell neighborhood around the processing or center cell. The direction of the plane (x,y-values) faces is the aspect for the

1 Landform is the result of various processes acting on the surface has also the function of a static boundary condition for processes in geomorphology, hydrology, meteorology, and others. Landform units can be extracted by delimiting homogeneous areas. 
processing cell. The slope for the cell is computed from the 3 x 3 cell neighborhood using the average maximum technique [6]. If there is a cell location in the neighborhood with a nodata $\mathrm{z}$ value, the $\mathrm{z}$ value of the center cell will be assigned to the location. At the edge of the grid, at least three cells (outside of the grid's extent) will contain nodata as their $\mathrm{z}$ values. These cells will be assigned to the center cell's $z$ value. The result is a flattening of the $3 \times 3$ plane that is fitted to these edge cells, which usually leads to a reduction in the slope. The formulas to compute the slope are:

$$
\begin{gathered}
\text { Rise_Run }=\sqrt{\sqrt{d z / d x}+\sqrt{d z / d y}}, \\
\text { Slope }=A \tan (\text { Rise_Run }) * 57.29578,
\end{gathered}
$$

where dz/dx and dz/dy are calculated using a 3 x 3 window (see Fig. 2) as described in equation 3 and 4 :

$$
\begin{aligned}
& d z / d x=((a+2 d+g)-(c+2 f+i)) /\left(8 * X_{-} \text {mesh_spacing }\right), \\
& d z / d y=((a+2 b+c)-(g+2 h+i)) /\left(8 * Y_{-} \text {mesh_spacing }\right),
\end{aligned}
$$

\begin{tabular}{|l|l|l|}
\hline a & b & c \\
\hline d & $e$ & $f$ \\
\hline g & h & i \\
\hline
\end{tabular}

Fig. 2. 3 x 3 window to compute slope

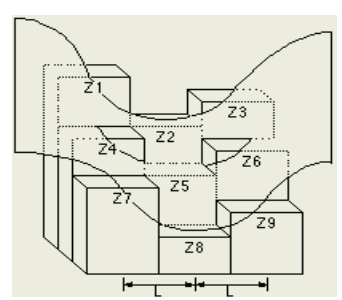

Fig. 3. Description of elements to compute the curvature

- Curvature Functions: This functions compute the curvature in a DEM. The curvature functions can be used to describe the physical characteristics of a drainage basin to understand erosion and runoff processes. Two types of curvatures can be obtained by using SAM.

1) Profile curvature (CALCULATE_PROFILE_CURVATURE) is the curvature of topography from a cross-section view (perpendicular to contour lines). 2) Plan curvature (CALCULATE_PLAN_CURVATURE) is the curvature of topography from a map view (following contour lines). The curvature of a surface is computed on a cell-bycell. For each cell, we use a fourth-order polynomial of the form [7]:

$$
Z=A x^{2} y^{2}+B x^{2} y+C x y^{2}+D x^{2}+E y^{2}+F x y+G x+H y+I,
$$

Equation 5, it is used to fit a surface composed of a $3 \times 3$ window. The coefficients from $A$ to $I$ are calculated from this surface. The relationships between the coefficients and the nine values of elevation for every cell numbered are shown in Fig. 3, and they are defined by equations 6 to 14 .

$$
\mathrm{A}=\frac{\left[\frac{(\mathrm{z} 1+\mathrm{z} 3+\mathrm{z} 7+\mathrm{z} 9)}{4}-\frac{(\mathrm{z} 2+\mathrm{z} 4+\mathrm{z} 6+\mathrm{z} 8)}{2}+\mathrm{z} 5\right]}{L 4},
$$




$$
\begin{gathered}
\mathrm{B}=\frac{\left[\frac{(\mathrm{z} 1+\mathrm{z} 3-\mathrm{z} 7-\mathrm{z} 9)}{4}-\frac{(\mathrm{z} 2-\mathrm{z} 8)}{2}\right]}{L 3}, \\
\mathrm{C}=\frac{\left[\frac{(-\mathrm{z} 1+\mathrm{z} 3-\mathrm{z} 7+\mathrm{z} 9)}{4}+\frac{(\mathrm{z} 4-\mathrm{z} 6)}{2}\right]}{L 3}, \\
\mathrm{D}=\frac{\left[\frac{(\mathrm{z} 4+\mathrm{z} 6)}{2}+z 5\right]}{L 2}, \\
\mathrm{E}=\frac{\left[\frac{(\mathrm{z} 2+\mathrm{z} 8)}{2}-z 5\right]}{L 2}, \\
\mathrm{~F}=\frac{(-z 1+z 3+z 7-z 9)}{4 L 2}, \\
\mathrm{G}=\frac{(-z 4+z 6)}{2 L}, \\
\mathrm{H}=\frac{(z 2-z 8)}{L 2}, \\
\mathrm{I}=z 5,
\end{gathered}
$$

The output of the CURVATURE function is the second derivative of the surface (i.e., the slope of the slope), which is defined in equation 15.

$$
\text { Curvature }=-2(D+E) * 100,
$$

The slope affects the overall rate of movement downslope. The Profile curvature impacts the acceleration and deceleration of the water flow. Therefore, it influences in the erosion and the deposition processes. The Plan curvature affects convergence and divergence of the water flow [8].

- Overlay Function (OVERLAY). This operation has been designed to generate multi-valued raster, which can be used to combine different geo-images. It is to count rasters with more than one attribute and assign values to these attributes for each raster elements [4]. The representation schema of the data structure is shown in Fig. 4. It is important to note that two rasters can only be overlaid if they have the same geometry.

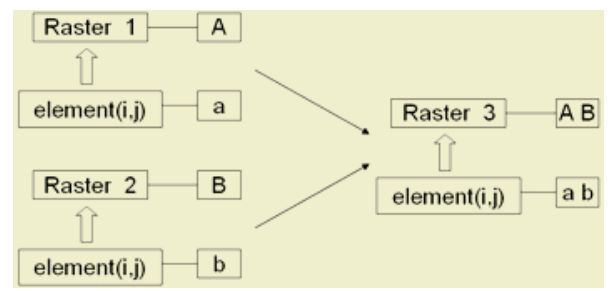

Fig. 4. Construction of multi-valued rasters 


\subsection{List of Procedures}

It stores the set of procedures for each one of the analysis processes, describes the required data type and the constraints. SAM has a wide range of applications, not only to make Landform classification but also to perform the detection of landslide and flooding areas [3].

\section{Landform Classification}

Primary and secondary attributes have been used to classify DEM into different landforms. A method by Pennock described in [9] was implemented to automatic classification. The distribution of the landform elements is depicted in Fig. 5.

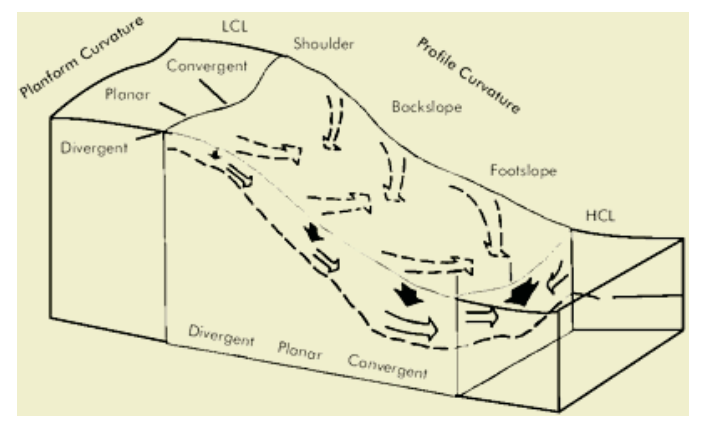

Fig. 5. Landform elements distribution

The slope, profile curvature and plan curvature have used to classify eleven different landforms (see Table 1). The landform classification is considered to evaluate the probable water movement and concentrations. Watershed is an area that drains water and other substances to common outlet as concentrated drainage. This area is normally defined as the total area flowing to a given outlet or pour point [8]. These areas are defined by WATERSHED function (Arc/Info).

Table 1. Classification of landform elements for a DEM with resolution of $10 \mathrm{~m}$

\begin{tabular}{|c|c|c|c|c|c|}
\hline $\begin{array}{c}\text { Landform } \\
\text { Elements }\end{array}$ & $\begin{array}{c}\text { Acro- } \\
\text { nym }\end{array}$ & Slope & $\begin{array}{c}\text { Profile } \\
\text { Curvature }\end{array}$ & $\begin{array}{c}\text { Plan } \\
\text { Curvature }\end{array}$ & $\begin{array}{c}\text { Water- } \\
\text { shead }\end{array}$ \\
\hline Divergent Shoulder & DHS & $>0$ & $>0.1$ & $>0.1$ & NA \\
Planar Shoulder & PSH & $>0$ & $>0.1$ & $>0.1>-0.1$ & NA \\
Convergent Shoulder & CSH & $>0$ & $>0.1$ & $>0.1$ & NA \\
Divergent BlackSlope & DBS & $>3.0$ & $>-0.1<0.1$ & $>0.1$ & NA \\
Planar BackSlope & PBS & $>3.0$ & $>-0.1<0.1$ & $>0.1<0.1$ & NA \\
Convergent BackSlope & CBS & $>3.0$ & $>-0.1<0.1$ & $>0.1$ & NA \\
Divergent FootSlope & DFS & $>0$ & $>-0.1$ & $>0.1$ & NA \\
Planar FootSlope & PFS & $>0$ & $>-0.1$ & $>0.1<0.1$ & NA \\
Convergent FootSlope & CFS & $>0$ & $>-0.1$ & $>0.1$ & NA \\
Low Catchment Level* & LCL & $<3.0$ & $>-0.1$ & NA & $<500$ \\
High Catchment Level* & HCL & $<3.0$ & $>-0.1$ & NA & $>500$ \\
\hline
\end{tabular}


The following pseudo-code has been designed to generate the landform classification:

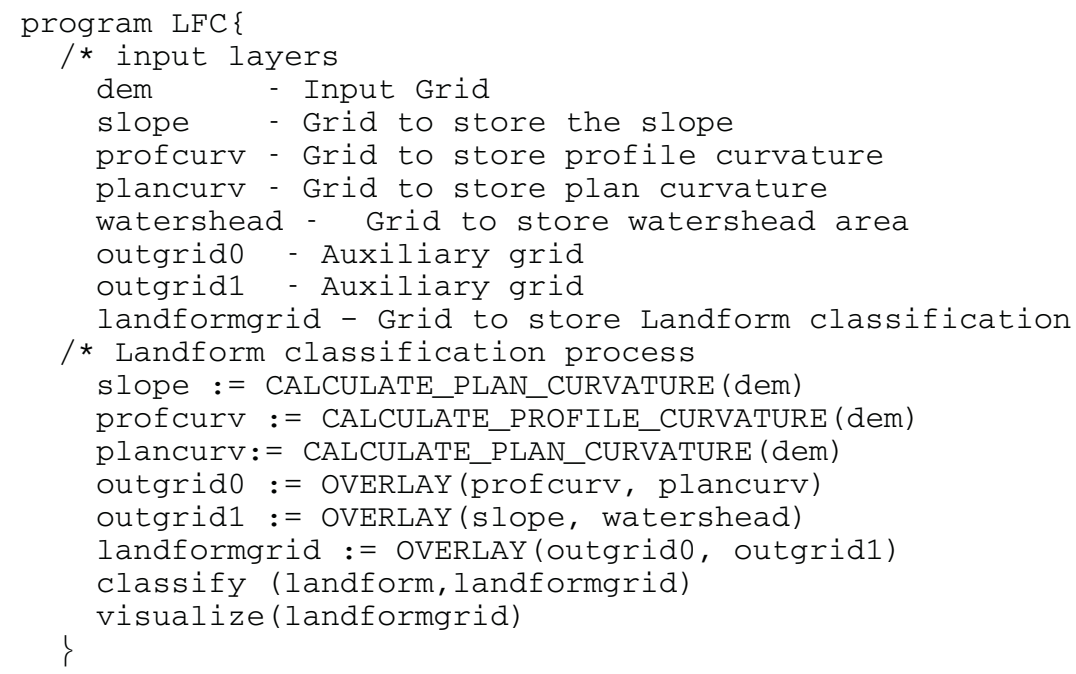

\section{Results}

By using SAM, we classify DEM. The algorithm has been applied to Tamaulipas State, Mexico. Some results are presented in this section. Tamaulipas State area is covered by DEM at two resolutions, $10 \times 10 \mathrm{~m}$ and $100 \times 100 \mathrm{~m}$, generated in GEOLAB, interpolating line contours. The spatial data reference is UTM projection. In this case, we use two DEM of the same zone in two resolutions: 1) 1925 rows and 2410 columns (10 meter resolution), 2) 190 rows and 239 columns (100 meter resolution); see Fig 6. Fig. $6 \mathrm{c}$ and $6 \mathrm{~d}$ show the landform classification of the DEM. The differences between these figures are due to the resolutions. Fig. $6 \mathrm{c}$ has more level of detail than Fig 6d. The favorite value in both classifications is Planar Back Slope, meaning that the terrain is mainly planar (this is its semantics).

\section{Conclusion}

In this work, we propose the Spatial Analyzer Module integrated into GIS-application to analyze landform characteristics of geo-images. SAM generates primary attributes of DEM to detect landform elements in raster image data. In this approach, spatial and attributive data are used to generate raster. Using SAM, it is possible to define the essential characteristics of the raster spatial data.

This raster analysis is traditionally performed by using the methods based on topographic map-processing in manual way. Our approach significantly decreases the amount of time and effort required to quantify selected terrain characteristics. Other methods are designed to evaluate additional characteristics, which are different to the properties proposed in our approach. However, these methods can be integrated into SAM. 


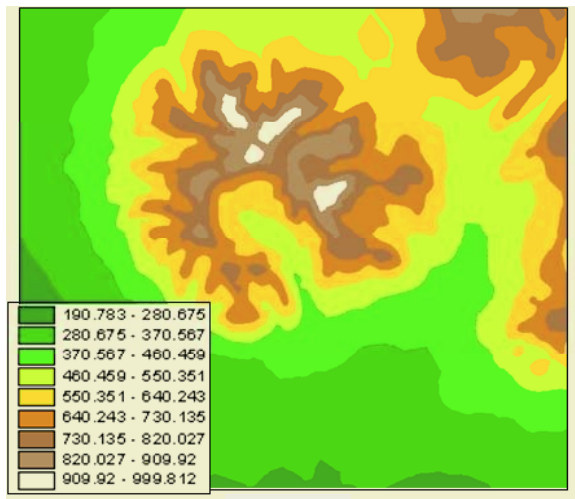

a)

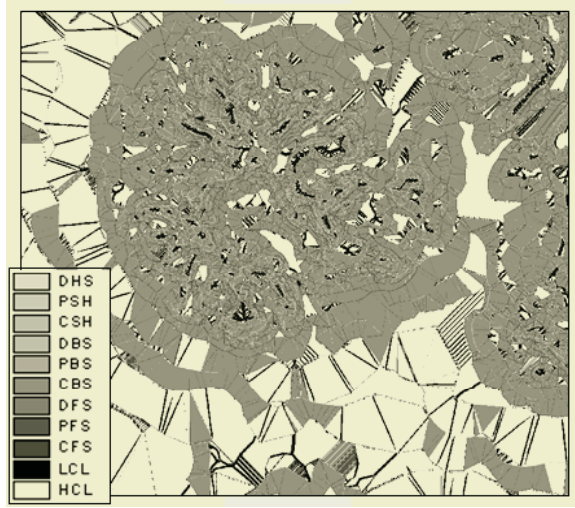

c)

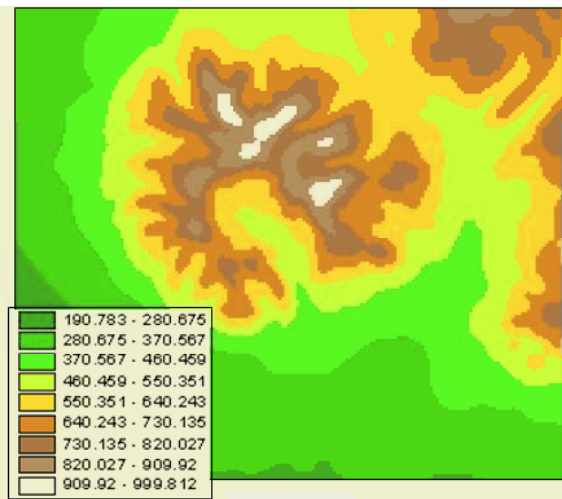

b)

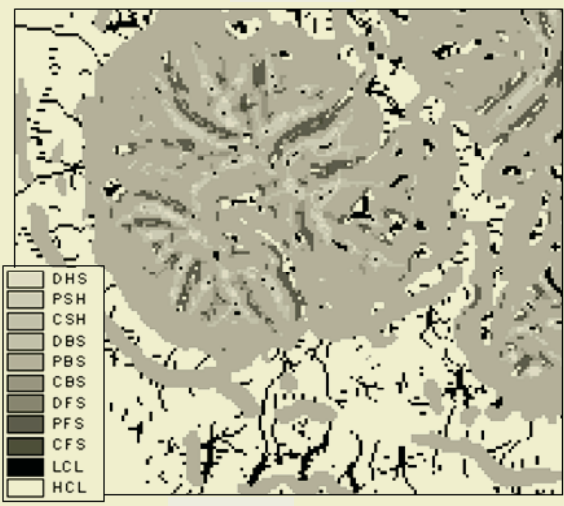

d)

Fig. 6. a) DEM with resolution of $10 \mathrm{~m}$, b) DEM with resolution of $100 \mathrm{~m}$, c) Landform classification of DEM with resolution of $10 \mathrm{~m}$, d) Landform classification of DEM with resolution of $100 \mathrm{~m}$

The generation of the landform layer facilitates the extraction-information of the spatial properties that can be used in other cartographic processes such as hydrological balance, automatic map description, identification of risk areas, map generalization, etc. Moreover, the landform classification approach is used to identify flooding areas and the path of the hydrological flows. Also, we can catch the semantics of DEM.

Acknowledgments. The authors of this paper wish to thank the CIC, CGPI, IPN and CONACYT for their support.

\section{References}

1. Goodchild, M.: Perspective: Browsing metadata, where do we go from here?, Vol. 10, Geo Info Systems, (2000), 30-31.

2. Wharton, G.: Progress in the use of drainage network indices for rainfall-runoff modelling and runoff prediction. Progress in Physical Geography, Vol. 18, (1994), 539-557. 
3. Moreno, M., Levachkine, S, Torres, M. Quintero, R.: Geomorphometric Analysis of Raster Image Data to detect Terrain Ruggedness and Drainage Density. Speech and Image Analysis in A. Sanfeliu and J. Ruiz-Shulcloper (Eds), LNCS 2905, Springer-Verlag, Berlin Heidelberg, 2003, 643-650.

4. Molenaar, M.: An Introduction to the theory of spatial object modelling for GIS. Taylor \& Francis, U.K., (1998).

5. Torres, M., Moreno, M., Menchaca, R. and Levachkine, S.: Making Spatial Analysis with a Distributed Geographical Information System, Series on APPLIED INFORMATICS - AI 2003, International Conference on Databases and Applications (DBA'2003), International Association of Science and Technology for Development (2003), 1245-12506.

6. Burrough, P.A.. Principles of Geographical Information Systems for Land Resources Assessment. Oxford University Press, New York, (1986).

7. Moore, I. D., Grayson, R. B., and Landson, A.: Digital Terrain Modelling: a Review of Hydrological, Geomorphological, and Biological Applications, Hydrological Processes. Vol. 5.3-30, (1999).

8. Zeverbergen, L. W., and C. R. Thorne: Quantitative Analysis of Land Surface Topography, Earth Surface Processes and Landforms, Vol. 12, (1987), 47-56.

9. Pennock, D.J., Zebarth, B.J. and de Jong, ELandform classification and soil distribution in hummocky terrain, Sasketchewan, Canada, Geoderma. 40, (1997), 297-315. 